\title{
Perspectives on Successfully Implementing BME Design Courses Online: Notes from an ASEE Workshop
}

\author{
William H. Guilford (i) ${ }^{1}$ and Rachael H. Schmedlen ${ }^{2}$ \\ ${ }^{1}$ Biomedical Engineering, University of Virginia, Charlottesville, VA, USA; and ${ }^{2}$ Biomedical Engineering, University of \\ Michigan, Ann Arbor, MI, USA
}

(Received 30 June 2020; accepted 24 August 2020; published online 3 September 2020)

Challenge: All college-level classes were affected by the emergency transition to online instruction when COVID-19 took on pandemic proportions. ${ }^{6}$ Engineering design courses were, at least according to anecdotal reports, disproportionately impacted. Most biomedical engineering design courses are intrinsically hands-on and team-based. The authors found through their own experiences as design instructors and through discussions with others that the abrupt transition online had certain common effects on design instruction:

- Building and testing of physical objects for the most part ceased.

- The physical separation of team members limited their ability to work collaboratively on tasks.

- Kits, tools, and other items were often left in student apartments and dormitories and so were unavailable to them for half of the semester.

- Computationally-intensive software or software with restrictive licenses were sometimes unavailable to students or difficult to run remotely due to limited bandwidth or the computational power of laptop computers.

As a result, few assignments in a typical design course that remained after mid-semester of Spring 2020 could be completed as originally developed, and had to be modified, replaced, or omitted entirely. Design courses that involved clinical observation or immersion were even more profoundly affected because students were not allowed to enter most clinical environments. In fact, clinical immersion programs are unlikely to resume in the current year. ${ }^{3}$

BME design instructors are seeking ways for students to work as a team in a physically-distanced

Address correspondence to Rachael H. Schmedlen, Biomedical Engineering, University of Michigan, Ann Arbor, MI, USA. Electronic mail: shope@umich.edu manner on projects that differ as little as possible from the semesters leading up to the pandemic, and they need to do so under highly restrictive conditions in the 2020-21 academic year. The pedagogical literature offers few clues as to how to accomplish this goal. For example, the format and outcomes of online capstone experiences have been reviewed, revealing increases in time commitment for student and instructor alike. ${ }^{1}$ However, this review did not touch on engineering design specifically. A report on a first-year engineering design course whose lectures moved online showed comparable results to face-to-face instruction, but the studio and fabrication components of those courses were still held face-to-face. ${ }^{8}$ We lack an effective guide for teaching engineering design in hybrid and wholly online contexts.

Innovation: Here we catalogue innovative approaches used by faculty around the country to effectively teach design courses online. To document these approaches, we organized a workshop at the 2020 ASEE Virtual Conference and Exposition titled "BME Design in the COVID-19 Era and How to Share Your Findings." The objective was not to review the failings of design courses during the transition to online; after all, the conditions surrounding the coming academic year are known in advance, and so any related failings should be viewed as a failure to plan. Rather, we sought perspectives from the approximately 43 attendees from at least 18 different institutions on:

1. what went well in their design courses after the transition to online instruction,

2. what additional or unique challenges will be posed by the return to some on-campus instruction in the fall, and

3. how we might collectively meet those challenges given what we know about what worked well. 
Attendees taught a range of courses from first-year design through capstone. They interacted via five breakout rooms in Zoom video conferencing software (Zoom Video Communications, Inc.), and were given approximately eight minutes to discuss each of the above three questions and create "sticky notes" of their contributions to the conversation using Jamboard digital whiteboard (Google LLC). Attendees were randomly assigned to breakout rooms and new groups were formed for each round/question. A few attendees were not themselves design instructors, and they were asked to contribute perspectives that would apply equally well to a design course as to their own. The resulting Jamboard was downloaded as a PDF file and is provided as a supplement to this paper.

The workshop attendees had widely varying answers when responding to the prompt "What went well in your design courses in Spring 2020?" yet three common themes emerged. First, there were hands-on design activities that continued even from students' homes. The use of digital electronics learning packages like MyDAQ, Arduino, and Raspberry Pi was common among these, as was instruction and use of computer-aided design (CAD). Second, the virtual environment created opportunities to focus on enhancing students' communications skills, enhance student engagement, and leverage third-party online products and platforms. These included

- oral presentations delivered on video conferencing platforms (e.g. Zoom) allow for an expanded audience or online poster sessions that provided better focus on the project highlights

- alternative final deliverables, e.g. videos of testing design projects, or creation of GoogleSites to highlight work

- collaboration and sharing software like Piazza (Piazza Technologies), GitHub (GitHub Inc.), and Instructables.com

- audience response and polling platforms like Mentimeter (Mentimeter AB), Poll Everywhere, and Questionpress (Polar Dynamics, LLC), and

- sites to build skills like MATLAB Academy (The Mathworks, Inc.).

Third, attendees noted certain positive effects on their students, including improvements in creativity, resourcefulness, and the use of common and low-cost materials for prototyping. Interestingly, a wide range of alternative design activities were employed by the attendees in place of build-test. These included

- design simulation and optimization,

- emphasis on front-end design and planning,

- formulation of robust testing plans,
- emphasis on design transfer,

- generation of high-quality manufacturing drawings,

- creation of a business plan, and

- development of packaging requirements.

We next prompted attendees with the question "What new challenges will design courses face in the Fall?" In this instance there was much greater agreement and four major themes emerged. The most common of these was concern about students' ability to build working relationships with their teammates when physical distancing is enforced, and when not all students will be able (or willing) to return to campus at all. Another, related concern was expressed for the learning and integration of students in different time zones. A third challenge is one of physical distancing and between-use disinfection in shops and studios. The needs for distancing and disinfection raise concerns of equitable access to hands-on learning. A final concern is for the accessibility of clients; obviously in-person meetings will be restricted, and there was a metamessage to the point that clients may be more difficult to find under the anticipated circumstances.

Reflection: In an effort to get attendees to reflect on lessons learned from the Spring of 2020, we prompted attendees with the question "How are you going to use what went well to address the challenges of the Fall?" On the challenge of students working effectively as teams when physical distancing is the norm and some teammates are present only virtually, it has long been known that students can work effectively as teams in a virtual environment, but that they find doing so to be much less satisfying than face-to-face teamwork. ${ }^{5}$ However, in an increasingly globally connected world, there is a growing need for engineers to develop strong virtual teamwork skills. Workshop attendees identified a number of different utilities for remote work that could be of use to engineers, including Miro (miro.com) and Jamboard for online, asynchronous brainstorming, Skedda (skedda.com) for calendaring, and Fusion 360 (Autodesk) for CAD. There was also mention of teaming students by time zone as a possible strategy, and of teaching students how to work effectively as a team in a virtual setting. An approach to teaching students to work online as a team has been proposed by others ${ }^{7}$ and includes seven defined steps (including the creation of virtual work and storage spaces), and four sub-steps to each: rationale for the step, implementation of the step, recommendations for how to do it, and technological options to enable the step.

To address the issue of shop and studio accessibility, several attendees suggested that students could design parts and assemblies to be built or assembled by the 
instructor, a teaching assistant, or by other students. This would indeed lessen the need for shop or studio space at any given time and may reinforce the lessons on team-based design and the importance of communication to a different audience - the machinist. At least one attendee suggested eliminating build-test activities altogether. As a caution, though, some attendees questioned whether this approach would impact students' psychomotor development. Indeed, Ferris and Aziz wrote:

In engineering it is necessary for the student to develop skills working with the tangible stuff related to the discipline because the role of an engineer is to do either or both of development work of products and systems and to direct other people in the development and manufacture of products and systems. ${ }^{2}$

Other specific strategies were recommended concerning shop and studio access, including drop-boxes for used tools so that they can be disinfected, and rotating one team at a time through shops to enable work as a team while lessening the risk of infection.

Few solutions were offered to the question of how best to work with clients, except to lessen the need for large numbers of clients. More than one attendee recommended having multiple teams work on a single project.

Curiously, some things that worked well in the emergency shift to online instruction during Spring 2020 and raised in the first breakout session were less discussed in the second and third breakout sessions .

The authors can, on the basis of these discussions and the literature, make several recommendations for BME design courses in the coming academic year, where some portion of the students will unquestionably be learning and participating remotely:

1. Multiple student teams working on a small subset of clinical problems (or only a single problem) reduces the need for clients at a time when many businesses are struggling. It anecdotally reduces the breadth of tools and materials needed to realize a solution, though it may simultaneously increase sharing of tools and materials-something to be avoided when possible to reduce the chance of cross-contamination. It may also increase the advising burden on individual clients. Instructors will have to find a balance appropriate for their class.

2. An increased or renewed focus on writing, communication, and effective teamwork is likewise a promising strategy for design courses in the coming academic year. The effectiveness of these strategies may be enhanced rather than impeded in online learning environments.

3. While it is tempting to reduce or eliminate student exposure to fabrication as part of their design training under these circumstances, we believe that switching entirely to virtual design work and simulation would be detrimental to students' education. In fact, individual technical competency in this domain should be preserved if at all possible. Adding additional shop or studio hours, rotating teams, simplifying projects, and reducing the number of skills students are expected to acquire are all promising strategies to this end.

4. Finally, it is important to learn from the positive experiences of our emergency transition to wholly online instruction. Things that worked well under those circumstances are likely to continue working well in the coming academic year, and even after a return to normal instruction. For example, learning kits with electronics and microcontrollers have proved useful for at-home learning ${ }^{4}$ and can be equally useful in beginner design classes and in open-ended design challenges like capstone projects. They can be managed either as a loan from the school to the student, or as a student purchase in lieu of or in addition to a textbook.

\section{ELECTRONIC SUPPLEMENTARY MATERIAL}

The online version of this article (https://doi.org/10. 1007/s43683-020-00026-9) contains supplementary material, which is available to authorized users.

\section{AUTHOR CONTRIBUTIONS}

Dr. Schmedlen organized the workshop. Drs. Schmedlen and Guilford contributed equally to the manuscript.

\section{DATA AVAILABILITY}

Data collected during the workshop are attached as a supplemental file.

\section{REFERENCES}

\footnotetext{
${ }^{1}$ Bharathi AKBG, Tucker CS. Investigating the impact of interactive immersive virtual reality environments in enhancing task performance in online engineering design activities. In: Presented at the ASME 2015 international design engineering technical conferences and computers and information in engineering conference, Jan 2016. https://doi. org/10.1115/DETC2015-47388.
} 
${ }^{2}$ Ferris T, Aziz S. A psychomotor skills extension to Bloom's taxonomy of education objectives for engineering education. In: Exploring innovation in education and research, Tainan, Taiwan; 2005, p. 1-6.

${ }^{3}$ Keeley M. Personal communication on the continuation of a clinical immersion program for biomedical engineering students. 2020.

${ }^{4}$ Meehan K, Cartwright JA. Lab-in-a-box: strategies to teach online lab courses while maintaining course learning objectives and outcomes. 2013, p. 23.842.1-23.842.8. https://pee r.asee.org/lab-in-a-box-strategies-to-teach-online-lab-course s-while-maintaining-course-learning-objectives-and-outcom es. Accessed 21 Jul 2020.

${ }^{5}$ Ocker RJ, Yaverbaum GJ. Asynchronous computer-mediated communication versus face-to-face collaboration: results on student learning, quality and satisfaction. Group Decis. Negot. 1999;8(5):427-40. https://doi.org/10.1023/A: 1008621827601 .
${ }^{6}$ Schlesselman LS. Perspective from a teaching and learning center during emergency remote teaching. Am. J. Pharm. Educ. 2020. https://doi.org/10.5688/ajpe8142.

${ }^{7}$ Stewart S. Chapter 5: guidelines for working collaboratively in virtual teams. In: Stevenson C, Bauer J, editors. Enriching collaboration and communication in online learning communities. Pennsylvania: IGI Global; 2019.

${ }^{8} \mathrm{Wu}$ LL, Fischer C, Rodriguez F, Washington GN. Evaluation of online learning in a first-year engineering design course. In: Presented at the 2018 ASEE annual conference \& exposition, Jun 2018. https://peer.asee.org/evaluation-of-on line-learning-in-a-first-year-engineering-design-course. Accessed 20 Jul 2020.

Publisher's Note Springer Nature remains neutral with regard to jurisdictional claims in published maps and institutional affiliations. 